\title{
Factors that inhibit adherence of Treponema pallidum (Nichols strain) to a human fibroblastic cell line: development in serum of patients with syphilis
}

\author{
J J VAN DER SLUIS, J A M KOEHORST, AND A M BOER \\ From the Department of Dermatovenereology, Erasmus University, Rotterdam, the Netherlands
}

SUMMARY Serum samples from 25 patients at five different stages of syphilis were investigated for their ability to inhibit the adherence of pathogenic Nichols treponemes to cultured human fibroblasts. Serum taken from patients at the end of the primary stage showed an appreciable inhibition of treponemal adherence, and maximum inhibition of adherence was produced by serum from patients with secondary syphilis. Some freshly harvested treponemal suspensions were resistant to the adherence inhibition factors in serum from patients with syphilis; after incubation in vitro for 24 hours this resistance was lost. In vitro incubation almost doubled the number of adherent treponemes/ fibroblast. These phenomena are discussed in terms of loss and reconstruction of the treponemal outer envelope. This leads to the suggestion that adherence occurs not only at the tips of the treponemes, but that surface components are also implicated, possibly as an initial contact mechanism. The composition of the outer envelope may in this way determine localisation versus dissemination of the treponemes.

\section{Introduction}

Cocultivation of pathogenic Treponema pallidum with tissue culture cells results in the micro-organisms attaching to the cells. ${ }^{12}$ This adherence prolongs the period of treponemal viability, as shown by the retention of motility ${ }^{12}$ and virulence. ${ }^{3}$ Pathogenic $T$ pallidum adhere to a wide variety of human and animal cell types in culture. ${ }^{2}$ In contrast, nonpathogenic treponemes and killed pathogenic treponemes do not adhere to tissue culture cells. ${ }^{2}$ $T$ pallidum adhere to the cells by one or both tips. This mode of attachment suggests that the receptors for attachment of the treponemes are located on their tips. ${ }^{1}$ ${ }^{2}$ It is not known to which cell surface components the treponemes attach, but as similar numbers attach to the entire outer surface of each cell, these components may be present on the entire surface of all cells. The presence of receptors on pathogenic $T$ pallidum and their absence from non-pathogenic species has led to the assumption that these structures represent an important factor in the initiation of treponemal infection in the host. Interestingly, a recent study of the successful in vitro propagation of Nichols pathogenic treponemes used a cocultivation system of treponemes

Address for reprints: Dr J J van der Sluis, Department of Dermatovenereology, Erasmus University, PO Box 1738, Rotterdam, the Netherlands

Accepted for publication 28 June 1986 and tissue culture cells. ${ }^{4}$ Taken together, these data indicate that intervention in the attachment of $T$ pallidum to host cells could prevent the infection. Immune serum from rabbits infected with $T$ pallidum has been shown to reduce the number of adherent treponemes in vitro. ${ }^{24}$ Wong et al showed that the development of adherence inhibiting factors in infected rabbits took longer than the development of antitreponemal antibodies. ${ }^{5}$ Adherence inhibiting factors can be convincingly shown about one month after an immunizing injection with treponemes. No data about the presence and the development of such factors during the course of syphilis in man are yet available. We report here the effect of infected and non-infected human serum on the attachment of Nichols pathogenic treponemes to a human fibroblastic cell line.

\section{Patients, materials, and methods}

\section{SERUM SAMPLES}

We obtained serum from patients with different stages of syphilis: seronegative, (SI-), seroconverting (SI \pm ), seropositive (SI+), secondary (SII), and late latent (LL). Samples were stored at $-70^{\circ} \mathrm{C}$ until used. We used serum from only patients in whom no concomitant disease was diagnosed. The age of patients with early syphilis ranged from 19 to 58 (mean 34 ) years and the age of patients with late latent syphilis ranged from 32 to 72 (mean 52) years. The case reports of the latter group of patients showed neither any previous 
history of syphilis nor treatment for syphilis. In all cases their sera gave positive results in the fluorescent treponemal antibody absorbed (FTA-ABS) reaction, whereas the cardiolipin test reactions were negative or only positive at a very low titre.

Control serum samples were obtained from seven healthy blood donors. One of these samples, of blood group $\mathbf{A B}$, was used as a reference serum throughout this study.

A standard set of serum samples was prepared as follows: one sample was selected randomly from each of the five diagnostic groups of the patients with syphilis. This resulted in a set of five samples that were used in the experiments with all the treponemal suspensions.

\section{EXTRACTION OF T PALLIDUM}

$T$ pallidum (Nichols pathogenic strain) was maintained in male New Zealand white rabbits as described previously. ${ }^{5}$ The treponemes were harvested from rabbit testes seven and 12 days after inoculation. In all cases orchitis was present. Treponemes were extracted as follows: minced testicular tissue was shaken for $\mathbf{4 5}$ minutes with an equal volume of sterile basal reduced medium $^{6}$ containing $20 \%$ heat inactivated fetal calf serum (Flow Laboratories) and $20 \mathrm{mg} \%$ (w/v) dithiothreitol. The extraction was performed in an atmosphere of $5 \%$ carbon dioxide and $95 \%$ nitrogen. The testicular extracts were centrifuged at $800 \times g$ at room temperature to sediment the particulate matter. Treponemes were counted using microslides as described previously. ${ }^{6}$ In preliminary experiments the treponemal density and percentage testicular extract seemed to influence the number of treponemes attaching to the cells. In all experiments, therefore, part of the treponemal suspension was centrifuged at $12000 \times \mathrm{g}$ for 10 minutes to obtain a supernate free from treponemes. The stock treponemal suspension was adjusted to $1 \times 10^{8}$ using this supernate. This suspension was subsequently diluted 10 times with fresh medium. The working suspension of treponemes thus contained $1 \times 10^{7}$ treponemes $/ \mathrm{ml}$ and $10 \%$ of the particular testicular extract. This suspension was then divided into $1 \mathrm{ml}$ aliquots in small tubes, which were loosely plugged with sterile gauze. Some of the tubes were used on the same day (direct experiments) and the others were stored for about 24 hours in a reduced oxygen atmosphere at $33^{\circ} \mathrm{C}$ (delayed experiments). As indicated in the results, fetal calf serum was omitted from the extraction medium in some experiments.

A reduced oxygen atmosphere was established in a dessicator, the final oxygen concentration being $4 \%$. This was achieved by evacuating the dessicator four times to a half atmosphere pressure measured by a manometer. The residual oxygen percentage was measured by a polarographic electrode (type 400 , Instrumentation Laboratories) previously calibrated using mixtures of pure nitrogen, pure oxygen, and atmospheric air as reference gases.

\section{FIBROBLASTS}

We used human cultured fibroblasts of cell line TR, which was maintained in glass $T$ flasks with F10 medium supplemented with 7\% fetal and 7\% new born calf serum (v/v) and penicillin or streptomycin. Confluent fibroblast layers were washed once with phosphate buffered saline (PBS), and the cells were loosened with trypsin (ICN catalogue No 103140). We then added $5 \mathrm{ml}$ medium and removed the suspended fibroblasts (split ratio 1:2). Plastic petri dishes $35 \times 10$ $\mathrm{mm}$, (Costar, No 3035) equipped with $20 \times 20 \mathrm{~mm}$ coverglasses and each containing $1.5 \mathrm{ml} \mathrm{F} 10$ medium were seeded with a drop of the fibroblast suspension and cultured to $25-50 \%$ confluency at $37^{\circ} \mathrm{C}$ in an atmosphere of $5 \%$ carbon dioxide in air. Before the fibroblasts were used in cocultivation experiments, the medium was removed and the cell layer rinsed once with PBS.

\section{COCULTIVATION OF FIBROBLASTS AND TREPONEMES} TREATED WITH SERUM

In the direct and the delayed experiments $0.75 \mathrm{ml}$ of the treponemal working suspension was mixed with $0.25 \mathrm{ml}$ heat inactivated serum and incubated for one hour at $33^{\circ} \mathrm{C}$ in a reduced oxygen atmosphere. The mixture was then added to the fibroblasts in the petri dishes and incubated at $33^{\circ} \mathrm{C}$ in reduced oxygen for two hours. (Preliminary experiments had shown that maximum numbers of treponemes adhered to the fibroblasts after this time.) The coverslips were then removed from the petri dishes and dipped in PBS to remove unattached treponemes. The coverslips were then laid upside down on the microscope slides and sealed with nail polish. The treponemes attached to the fibroblasts were counted by observing by dark field microscopy 50 fibroblasts from duplicate petri dishes. All serum samples were tested in direct and delayed experiments with treponemes obtained from rabbits seven and 12 days after inoculation. The samples from patients in one diagnostic group, together with the standard set of samples, were tested in direct and delayed experiments on two successive days with treponemes obtained from the same rabbit. Each treponemal suspension was described according to the diagnostic group tested. For instance, the treponemal suspension used to test the seropositive (SI+) serum was designated the $\mathrm{SI}+$ suspension.

Treponemal motility was measured in wet mounts by observing at least 100 treponemes using dark field microscopy. In all treponemal suspensions treponemal motility was almost $100 \%$ directly after extraction from rabbit testes. After overnight incubation in vitro, the motility of the various suspensions ranged from $88 \%$ to $96 \%$. At the end of the period of cocultivation 
with fibroblasts treponemal motility was judged from the treponemes still present in the liquid phase in each petri dish. In the direct experiments motility was invariably more than $90 \%$ whereas in the delayed experiments it ranged from $81 \%$ to $90 \%$. This shows that treponemal motility was not selectively affected by the added sera.

\section{Results}

To investigate whether serum present in the treponemal suspensions influenced their adherence, we used treponemes extracted in basal reduced medium (BRM) or BRM containing fetal calf serum (FCS). Table I shows that progressively fewer

TABLE 1 Mean (SD) adherence of Treponema pallidum (Nichols strain) to cultured human fibroblasts expressed as percentages of control values after adding $0.25 \mathrm{ml} B R M$, $F C S, A B$, or SII serum to $0 \cdot 75 \mathrm{ml} T$ pallidum suspension, extracted in either $B R M$ or $B R M$ and $F C S$

\begin{tabular}{|c|c|c|c|c|c|}
\hline \multirow{2}{*}{$\begin{array}{l}\text { Treponemes } \\
\text { suspended in: }\end{array}$} & \multirow[b]{2}{*}{$n$} & \multicolumn{4}{|c|}{ Addition of: } \\
\hline & & $B R M$ & FCS & $A B$ & SII \\
\hline $\begin{array}{l}\text { BRM } \\
\text { BRM+FCS }\end{array}$ & $\begin{array}{l}3 \\
3\end{array}$ & $\begin{array}{l}100 \\
100\end{array}$ & $\begin{array}{l}85.6(11.7) \\
91.9(6.0)\end{array}$ & $\begin{array}{l}74.8(3.2) \\
93.4(9.0)\end{array}$ & $\begin{array}{l}58.4(5.5) \\
65.0(2.3)\end{array}$ \\
\hline
\end{tabular}

BRM = basal reduced medium.

FCS $=$ fetal calf serum.

$\mathbf{A B}=$ control serum of blood group $\mathbf{A B}$.

SII = serum from patient with secondary syphilis.

treponemes adhered after adding FCS, AB, or SII serum to treponemes in BRM. This shows that under these conditions serum from non-infected people inhibits adherence. When the same serum samples were added to treponemes in medium containing FCS, however, only SII serum considerably reduced the number of adhering treponemes. We therefore studied adherence inhibition of serum from patients with syphilis using suspensions extracted in BRM and FCS. This also enabled us to study the effect of the sera after incubation of the treponemes overnight in vitro, as the presence of serum was essential for their survival.

Despite the standardisation of factors previously shown to influence treponemal adherence (final serum concentration, number of treponemes added, and the percentage of testicular extract), the absolute numbers of adherent treponemes/fibroblast varied considerably between the different treponemal suspensions (table II). This was true for direct and delayed experiments. A second feature shown in table II was an almost doubling of the number of adhering treponemes after in vitro incubation. This occurred with seven day as well as 12 day suspensions. The effects of the sera from patients with syphilis were therefore expressed as
TABLE II Absolute numbers of adherent Treponema pallidum (Nichols strain)/fibroblast in direct or delayed (24 hours later) experiments with treponemes harvested seven or 12 days after inoculation in rabbits and extracted in $B R M+F C S$ medium with $0.25 \mathrm{ml} A B$ serum added $/ \mathrm{ml}$ suspension

\begin{tabular}{|c|c|c|c|c|}
\hline \multirow[b]{2}{*}{$\begin{array}{l}\text { Treponemal } \\
\text { suspension }\end{array}$} & \multicolumn{2}{|c|}{7 day suspensions } & \multicolumn{2}{|c|}{12 day suspensions } \\
\hline & $\begin{array}{l}\text { Direct } \\
\text { expments }\end{array}$ & $\begin{array}{l}\text { Delayed } \\
\text { expments }\end{array}$ & $\begin{array}{l}\text { Direct } \\
\text { expments }\end{array}$ & $\begin{array}{l}\text { Delayed } \\
\text { expments }\end{array}$ \\
\hline $\begin{array}{l}\text { (SI-) } \\
\text { (SI }) \\
\text { (SI+) } \\
\text { (SII) } \\
\text { (LL) }\end{array}$ & $\begin{array}{r}9 \cdot 2 \\
10 \cdot 9 \\
9 \cdot 8 \\
17 \cdot 2 \\
13 \cdot 7\end{array}$ & $\begin{array}{l}19 \cdot 9 \\
19 \cdot 2 \\
19 \cdot 5 \\
27 \cdot 8 \\
24 \cdot 6\end{array}$ & $\begin{array}{r}7 \cdot 1 \\
11 \cdot 3 \\
18 \cdot 5 \\
12 \cdot 8 \\
8 \cdot 4\end{array}$ & $\begin{array}{l}15.9 \\
21.6 \\
26.6 \\
19.8 \\
16.5\end{array}$ \\
\hline Mean (SD) & $12 \cdot 2(3 \cdot 3)$ & $22 \cdot 2(3 \cdot 8)$ & $11 \cdot 6(4 \cdot 5)$ & $20 \cdot 1(4 \cdot 3)$ \\
\hline
\end{tabular}

BRM = basal reduced medium.

FCS = fetal calf serum.

* Suspensions used to test serum from patients with five stages of syphilis. SI- $=$ seronegative, SI $\pm=$ seroconverting, SI $+=$ seropositive; SII = secondary, $L L=$ late latent.

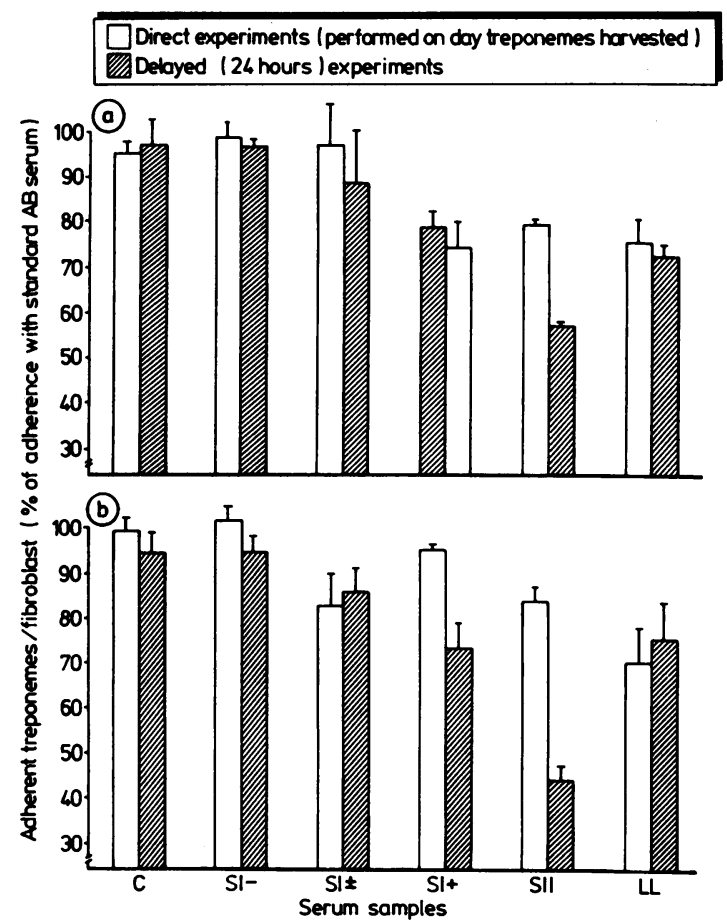

FIG 1 Inhibition of adherence of Treponema pallidum (Nichols strain) to human fibroblasts by serum from patients with five different stages of syphilis (SI- = seronegative, $S I \pm=$ seroconverting, $S I+=$ seropositive, $S I I=$ secondary, and $L L=$ late latent) and healthy controls (C) using treponemes harvested from rabbits seven days (a) and 12 days (b) after inoculation. 
percentage of the number adherent treponemes/ fibroblast after adding standard $\mathrm{AB}$ serum.

Figure 1 shows the effects of serum samples from the control and the five diagnostic groups. It can be seen that the control sera neither promoted nor inhibited the attachment of treponemes compared with the standard AB serum. In the delayed experiments the addition of sera from, patients at some stages of syphilis resulted in partial inhibition of treponemal adherence with seven and 12 days suspensions. With both seven and 12 day suspensions, the adherence of the treponemes was considerably reduced by serum from seropositive patients. The number of adhering treponemes differed from that adhering with control serum by more than one standard deviation. Maximum adherence inhibition was obtained by serum from patients with secondary syphilis in delayed experiments with seven day (44\% of adherence inhibited) and 12 day (57\% of adherence inhibited) suspensions. Serum from seroconverting patients exerted an intermediate effect; in the delayed experiments with 12 day suspensions the adherence differed one standard deviation from that of the control sera, whereas in the delayed experiments with seven day suspensions the degree of adherence overlapped with that of the control sera. Serum from patients with late latent syphilis inhibited adherence by about $25 \%$ with both seven and 12 day suspersions. As the motility of the treponemes at the end of the cocultivation period was between $81 \%$ and $90 \%$ in the delayed experiments, the reduced adherence was unlikely to have been caused by differences in treponemal motility due to incubation with different sera.

In the direct experiments, less clear cut results were obtained. With seven day suspensions the adherence inhibition produced by serum from patients with secondary syphilis was the same as that produced by serum from seropositive patients and those with late latent syphilis. In direct experiments with 12 day suspensions using the serum from seropositive patients and those with secondary syphilis, a resistance to adherence inhibition was seen. As shown in fig 1, these sera produced a definite adherence inhibition with the same treponemal suspensions that had been incubated overnight.

As the inhibitory activity of sera of patients with syphilis was analysed by diagnostic groups using one isolate of treponemes, it could not be shown whether this resistance was associated with the syphilitic sera or with the treponemal suspensions. The set of standard sera was therefore included in each experiment. Fig 2 shows the mean effect of these standard sera on the five seven day and five 12 day treponemal suspensions. In the experiments using seven day suspensions these standard sera produced a similar profile of adherence inhibition as was shown in fig 1(a) for the delayed experiments that used seven day suspensions. $\square$ Direct experiments (performed on day treponemes harvested Delayed (26 hours ) experiments

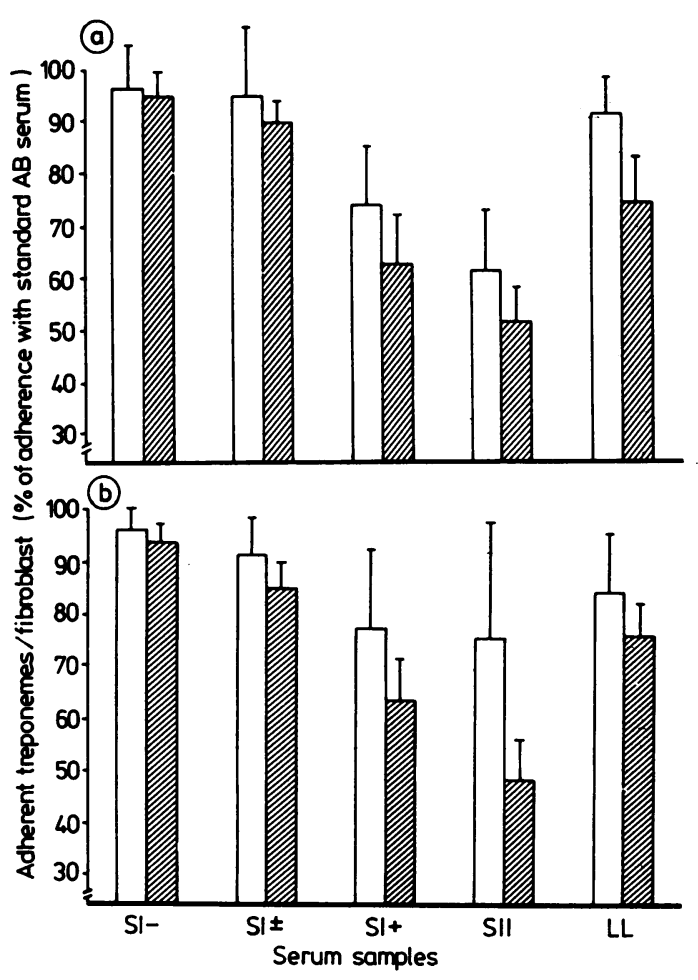

FIG 2 Mean inhibition of adherence of T pallidum (Nichols strain) to human fibroblasts by standard set of serum samples (see fig 1 for abbreviations) using five different treponemal suspensions with treponemes harvested from rabbits seven days (a) and 12 days (b) after inoculation.

With the directly used 12 day suspensions (fig 2(b)) the mean effect of standard sera from seropositive patients and those with secondary syphilis was only a modest reduction in the treponemal attachment. From the large standard deviation, however, it was clear that there was a wide variation in susceptibility to the adherence inhibition factors among these treponemal suspensions. The 12 day suspensions were susceptible to these factors in delayed experiments, and the standard deviation diminish $\supseteq d$ drastically. Fig 3 shows a typical example of the addition of the standard sera to a resistant treponemal suspension. It can be seen that such suspensions were, on the day of their isolation, almost completely insensitive to the adherence inhibitory factors in the whole set of standard sera.

\section{Discussion}

The results presented show that the addition to 


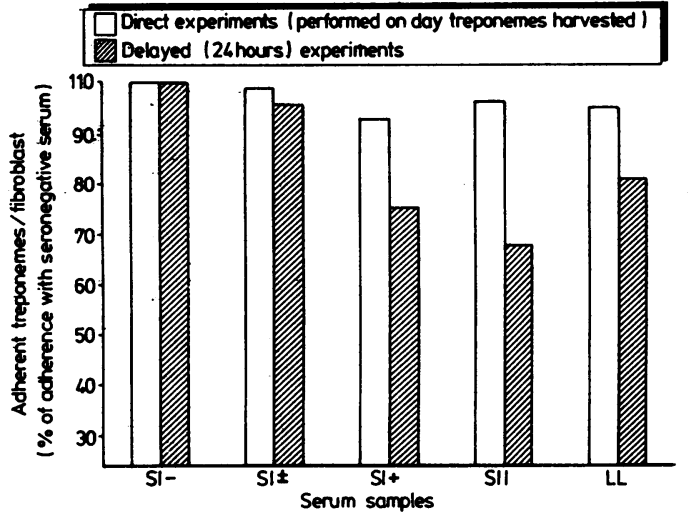

FIG 3 Inhibition of adherence of $T$ pallidum (Nichols strain) to human fibroblasts by set of standard serum samples (see fig 1 for abbreviations) using treponemes harvested from rabbits 12 days after inoculation.

treponemal suspensions of control serum as well as that from patients with syphilis reduces the attachment of treponemes to cultured human fibroblasts. This indicates that the serum samples contain factors that interfere with the adherence process. The serum samples from patients with syphilis exerted a stronger effect than those from the controls. This was especially apparent in the delayed experiments. Using serum samples from the sequential stages of classic syphilis in man, the ability of the syphilitic serum to inhibit adherence was first found to exceed that of the control serum at the end of the primary stage. It reached its maximum during the secondary stage and was still detectable during the late latent stage. This profile of development of adherence inhibition factors in these serum samples resembles that of serum immunoglobulin concentrations, ${ }^{7} 8$ antitreponemal antibody titres, ${ }^{8}$ and the numbers of treponemes assumed to be present during the course of infection.

Immune sera from syphilitic rabbits have been shown to contain adherence inhibition factors. ${ }^{1} 24$ Wong et al studied the development of these factors during the course of experimental syphilis. ${ }^{5}$ They showed that serum did not inhibit treponeme adherence until about one month after rabbits were inoculated, which was well after serological reactions, including those to the $T$ pallidum immobilisation (TPI) test, became positive. In the present study, the adherence inhibiton factors were at first shown during the seropositive stage. This stage is defined as the first stage of primary syphilis in which the four serological tests, including the TPI test, give positive results. ${ }^{9}$ In syphilis in man the development of adherence inhibition factors seems to parallel the development of the serological reactions more closely.

In the direct experiments the demonstration of adherence inhibition factors was more ambiguous. Some of the suspensions used were resistant to the adherence inhibiting action of serum from patients with syphilis. Our results strongly suggest that this resistance was associated with the treponemal suspensions themselves, rather than with the added sera, especially as this resistance was lost after incubation overnight. One explanation could be that these particular suspensions contained substances of either testicular or treponemal origin, which inactivated the adherence inhibiting components of the serum from patients with syphilis. In that case, the apparent absence of such factors after incubating the treponemal suspensions overnight in vitro could be due to the labile nature of the factors or because they were inactivated by the treponemes during incubation. A second explanation, which seems to be more plausible, is that the change in susceptibility to adherence inhibition factors after in vitro incubation was associated with changes in the treponemal surface. Freshly harvested treponemes have been shown to be covered with host proteins ${ }^{10}$ and with a slime layer probably consisting of mucopolysaccharides. ${ }^{11}$ Gradual dissipation of these substances from the treponemal surface during in vitro incubation could unmask treponemal surface components that act as adherence sites. The inability to detect reactions between antigen and antibody in certain serological tests that use freshly harvested treponemes has also been ascribed to the masking of treponemal components by an extracellular protective layer. ${ }^{12}$ The present observation that the absolute numbers of adhering treponemes increased appreciably after overnight incubation may also be explained in terms of exposure of the binding sites on the treponemal surface.

Adherence inhibition by serum from patients with syphilis could be explained by reoccupation of exposed treponemal sites by constituents from the added serum. Several authors have reported that the effect of syphilitic rabbit serum on treponemal adherence favours such a role for specific antibodies in adherence inhibition. ${ }^{124}$ The results with whole serum that was used in these studies, however, do not provide conclusive evidence that antibodies are the sole cause of adherence inhibition. Occupation of the exposed treponemal surface structures by serum components other than antibodies could probably also reduce the tendency of the treponemes to adhere to cultured cells. Alderete and Baseman identified several host serum proteins that are able to combine with the outer surface of treponemes. ${ }^{10}$ Peterson et al showed that washed $T$ pallidum avidly bind fibronectin to their surface. ${ }^{13}$ These authors also showed that this interaction used three outer envelope proteins of $T$ pallidum, which had previously been identified as possible receptor proteins in the adherence of $T$ pallidum to cultured cells. ${ }^{14}$ Fitzgerald and Repesh provided evidence that host 
fibronectin was present not only at the tips, but also on the entire outer surface of Nichols treponemes adhering to cells. ${ }^{15}$ Combination of these proteins with the exposed treponemal outer surface components could lead to the re-formation of a protective layer, which in turn could lead to diminished treponemal adherence. This would implicate the whole outer surface of treponemes in treponemal adherence. Electron microscope observations, however, have shown that treponemes adhere to cells by means of their tips, ${ }^{1}$ which suggests that exposed outer surface components of the treponemes might function as a first contact mechanism between treponemes and cultured cells.

The wide variation in the number of adhering treponemes per fibroblast using different treponemal suspensions suggests that the treponemes used in the present study differed in the composition of their extracellular layer. Suspensions resistant to the adherence inhibition factors of serum from patients with syphilis showed, in the direct experiments, an absolute number of adhering treponemes that was well above the mean for that particular group. This suggests that exposure of those treponemal components detected by serum from patients with syphilis is not an indispensible condition for adherence to occur. The adherence phenomenon may be divided in two processes, however, the first one being independent of the exposure of the sites influenced by serum from patients with syphilis and the second depending on the exposure of such sites. One could speculate whether the composition of the extracellular layer determines the selective localization of the treponemes in areas rich in connective tissue or the dissemination of the treponemes.

\section{References}

1. Hayes NS, Muse KE, Collier AM, Baseman JB. Parasitism of virulent Treponema pallidum of host cell surfaces. Infect Immun 1977;17:174-86.
2. Fitzgerald TJ, Johnson RC, Miller JN, Sykes JA. Characterization of the attachment of Treponema pallidum (Nichols strain) to cultured mammalian cells and the potential relationship of attachment to pathogenicity. Infect Immun 1977;18:467-79.

3. Fieldsteel AH, Becker FA, Stout JG. Prolonged survival of virulent Treponema pallidum (Nichols strain) in cell-free and tissue culture systems. Infect Immun 1977;18:173-82.

4. Fieldsteel AH, Cox DL, Moeckli RA. Cultivation of virulent Treponema pallidum in tissue culture. Infect Immun 1981;32:908-15.

5. Wong GHW, Steiner B, Graves S. Effect of syphilitic rabbit sera taken at different periods after infection on treponemal mobility, treponemal attachment to mammalian cells in vitro, and treponemal infection in rabbits. British Journal of Venereal Diseases 1983;59:220-4.

6. van der Sluis JJ, ten Kate FJW, Vuzevski VD, Kothe FC, Aelbers GMN, van Eijk RVW. Transfusion syphilis, survival of Treponema pallidum in donor blood. II. Dose dependence of experimentally determined survival times. Vox Sang 1985;49:390-9.

7. Delhanty JJ, Catterall RD. Immunoglobulins in syphilis. Lancet 1969;ii:1099-103.

8. Menke HE. Immunoglobulinen en thymoltroebeling by vroege syfilis. Rotterdam: Erasmus University, 1975. PhD thesis. 1-115.

9. de Jong NHL, van der Sluis JJ, van Dijk J, Feltkamp TEW. Epidermal antibodies in secondary syphilis. British Journal of Venereal Diseases 1978;54:283.

10. Alderete JF, Baseman JB. Surface associated host proteins on virulent Treponema pallidum. Infect Immun 1979;26:104856.

11. Zeigler JA, Jones AM, Jones RH, Kubica KM. Demonstration of extra-cellular material at the surface of Treponema pallidum cells. British Journal of Venereal Diseases 1976;52:1-8.

12. Hardy PH, Nell EE. Study of the antigenic structure of Treponema pallidum by specific agglutination. American Journal of Hygiene 1957;66:160-72.

13. Peterson KM, Baseman JB, Alderete JF. Treponema pallidum receptor binding sites interact with fibronectin. $J$ Exp Med 1983;157:1958-70.

14. Baseman JB, Hayes EC. Molecular characterization of receptor binding proteins and immunogens of virulent Treponema pallidum. J Exp Med 1980;151:573-86.

15. Fitzgerald TJ, Repesh LA. Interactions of fibronectin with Treponema pallidum. Genitourin Med 1985;61:147-55. 